\title{
Decision Making under COVID-19. A Possible Way to Mitigate the Crisis Impact. A Multidisciplinary View from Romania
}

\author{
Cristian CIUREA, Lorena BĂTĂGAN \\ Bucharest University of Economic Studies, Bucharest, Romania \\ Romanian Academy Library, Bucharest, Romania \\ cristian.ciurea@ie.ase.ro, lorena.batagan@ie.ase.ro
}

The paper presents a multidisciplinary view related to the impact of the COVID-19 pandemic on the educational and cultural fields, with particular cases and scenarios from Romania. Some aspects regarding the use of video conferencing technologies in the educational system are described, highlighting that the choice of a particular solution depends on the cultural profile of the users. Virtual Exhibitions are presented as one of the ways to mitigate the impact of the crisis in the cultural field. The development and use of Virtual Reading Rooms and Virtual Teaching Spaces, proposed by Research Libraries UK, is another solution to mitigate the crisis impact in educational and cultural sectors.

Keywords: Decision Making, COVID-19 Pandemic, Virtual Exhibitions, Education, Culture. DOI: $10.24818 /$ issn14531305/25.4.2021.03

1 Introduction

According to [1], one of the most challenging aspects of building a healthier community is that success is defined by whatever doesn't happen, a characteristic that is impossible to quantify to some extent.

The COVID-19 pandemic has demonstrated the significance of all businesses being prepared to deal with significant, unplanned change. Organizations that can successfully absorb and adapt to the challenges of the COVID-19 pandemic are resilient. Many people are also making decisions at a rate that would have been unthinkable prior to the COVID-19 outbreak [2].

To promote agility, five criteria were discovered across all enterprises [2]:

- Create frameworks that allow for swift decision-making, including resource reallocation to match changing priorities;

- Build networks of local teams with clear roles and duties;

- Build a common objective and better communication;

- Foster a culture that empowers helps motivate individuals to pursue their entrepreneurial ambitions;

- Ensure that people have access to the technologies they require.

According to [3], several collection-holding organizations have been actively investigating new and inventive ways to enable digital access to certain collections. The rise of the COVID-19 epidemic has increased this requirement. The closing of libraries, archives, and museums to researchers at the peak of the pandemic, as well as limited access during multiple periods of governmental lockdown and social distancing regulations, have severely hampered scholars' capacity to conduct research.

\section{The Impact of the Pandemic to the Educational System}

The educational system will undoubtedly experience considerable changes in the near future, both in terms of how courses are provided and how students in educational processes participate. Video conferencing platforms such as Zoom, Skype, Google Meet, Webex, Microsoft Teams, and a few others have been widely adopted not only for private purpose, but also as the primary solution available for the continuity of educational and business activities over the last two years [4]. When selecting a solution, consider not just the license costs, but also the functions supplied by each solution, how convenient it is to install and use it on both desktop and mobile devices, and other elements that have helped these platforms become so popular in 
such a short amount of time. These characteristics differ greatly and must be thoroughly evaluated before being used in a severe situation.

The cultural identity of the participants is an important factor in differentiating the use of web platforms for virtual meetings and other collaborative purposes. An examination of current video conferencing solution usage by gender, age, country, and educational level of participants would be very interesting. Individuals, organizations, communities, and countries all have various preferences when it comes to specific solutions.

Figure 1 depicts the statistics for Zoom attendance for 36 participants over a period of approximately 420 minutes for students enrolled in a master's degree program whose activities are taking place over the weekend.

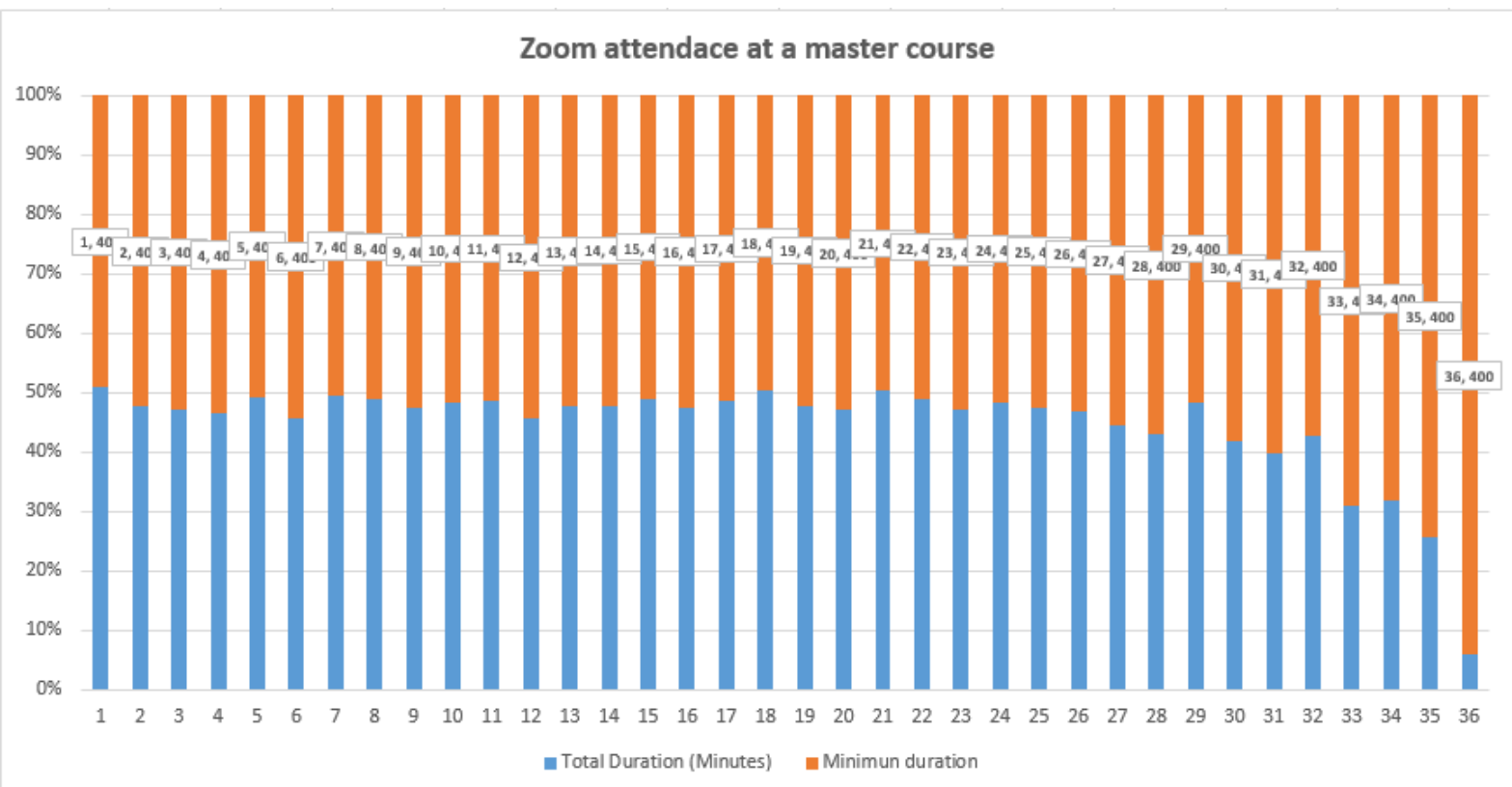

Fig. 1. An example of a master class's Zoom attendance data [4]

As a result, teacher interaction with students in the web - based learning environment is a significant problem.

As mentioned in [3], Virtual Reading Rooms (VRR) and Virtual Teaching Spaces (VTS) are new services that arose as a result of the COVID-19 pandemic. Despite their origins as a realistic response to building closures during various local, regional, and national lockdowns, VRRs and VTSs have become created as useful routes through which GLAM (galleries, libraries, archives, and museums) and universities can engage with different participants through virtual classroom meetings. The differences between VRR and VTSs are the related to use, application, destination and audience. While the VRR solutions are a bespoke research service between individuals, the VTSs allow the delivery of content to groups within a learning or teaching environment [10].

Scientists, research professors, and members of the public can digitally view and interact with an institution's cultural heritage and collections by using live broadcasts through physical reading rooms and learning facilities provided by GLAM institutions, requesting that they be positioned and questioned by a staff member to allow them to be researched or learned.

Virtual Reading Rooms, Virtual Teaching Spaces and also Virtual Exhibitions are new services that have grown in popularity as a result of the COVID-19 pandemic.

\section{Existing Solutions for the Management of COVID-19 Impact in the Educational System}

The COVID-19 pandemic affected the entire world. During this period most of the 
universities and cultural institutions around the world had decided to close for a period, and move to the online environment. The educations' deciders had tried to find the best solutions for this situation. During this period many cultural institutions and universities tried to find solutions for helping the students to access the information and for better interaction. Several studies ([12], [13], [14]) highlight that the most used solutions during COVID-19 pandemic period were Virtual Reading Rooms and Virtual Teaching Spaces. Manchester University brought a set of logistical and technical solutions and encouraged innovative human challenges from the beginning of the pandemic period. Manchester University and Manchester Library University provide access to VRR service since July 2021 [12]. Since then, they delivered over 235 sessions.

The students from the University of Economics in Slovakia can use the Virtual Reading Room [15] for documentation and interaction. The Slovak Economic Library, even before the pandemic period, established a VRR service (Virtual Reading Room EUBA) which offer the access to over 400 digitized publications [19].

According to [14], Reading University procured in September 2020 a Virtual Reading Room to enable the access to more online content. This solution increased the digital access and helped to better interaction of the students and help them to read more books.

From the beginning of pandemic period, Trinity College from Dublin had the priority the safety of staff and students, but in the same time they had wanted to facility the access at the resources for the continuity of the educational process. They invested in online library [16] (Figure 2), virtual consultations and online content and the result was that they continued to offer to the student's good facilities to learn.

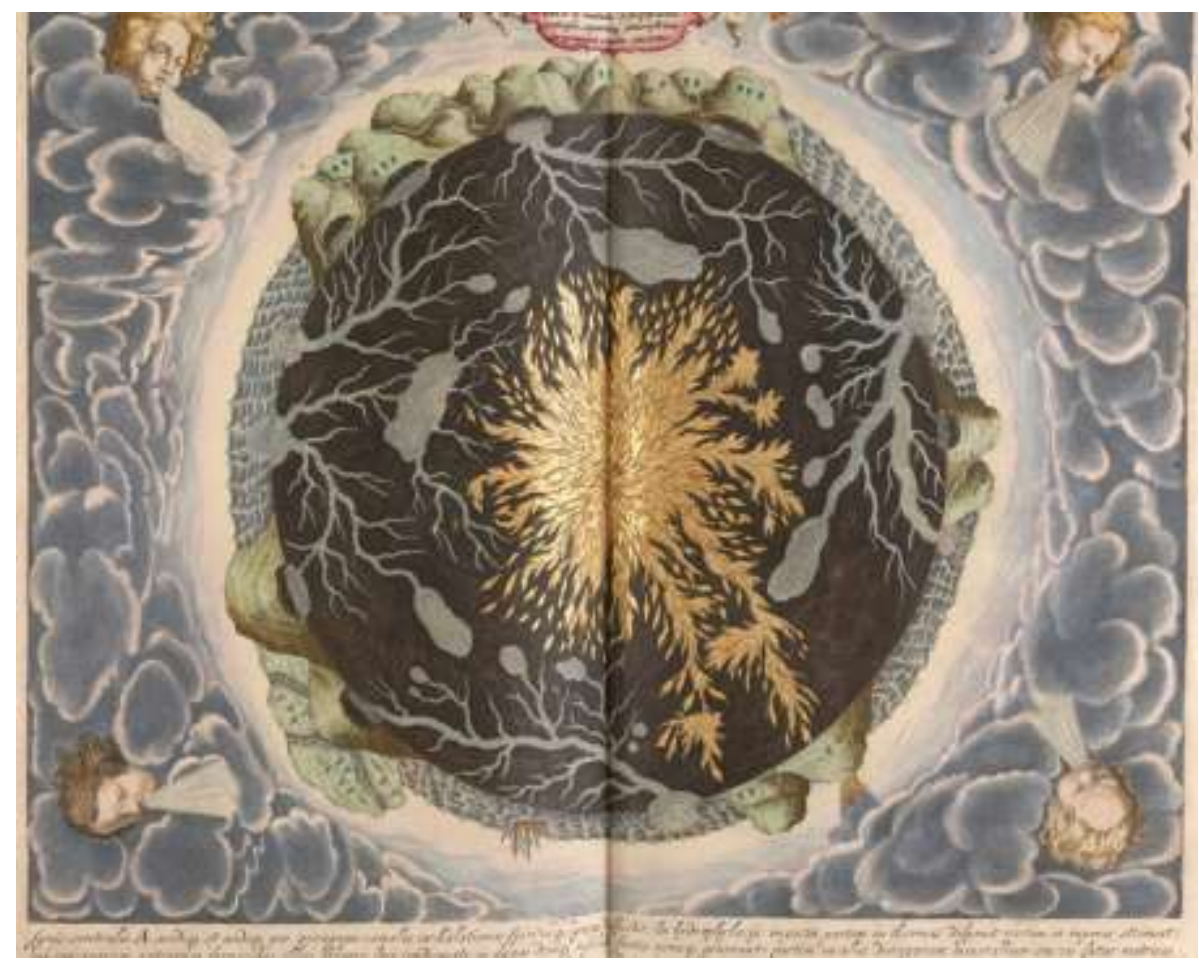

Fig. 2. Virtual Trinity Library - Trinity College Dublin [16]

In the last century, most of the universities, libraries and cultural institutions transformed the physical content in a digital one, but the pandemic period accelerated this process and the virtual reading room and virtual teaching spaces seem to be a real solution for future education and research.

Also, the University of Reding started a VRR service in September 2020 [20], providing access to Special Collections, Art Collections 
and Museum of English Rural Life (The MERL).

In 2021 Research Libraries UK published a report [10] in which they had made an international survey regarding the development and delivery of VRR and VTSs services. They received responses, from 32 institutions which highlighted the preoccupation regarding the virtual solutions for these universities and cultural institutions. Some of organizations already implemented such kind of services and they want to improve them (56\% have a VRR and $38 \%$ have a VTS), and other want to create them (44\% intend to create a VRR, 63\% intend to create a VTS). This report let us to see the big impact and the necessity of VRRs and VTSs in the pandemic period. A high number of these services had been created as a result of the COVID 19 pandemic, because they represent a real support for learning an evolution (figure 3 ).

\section{Chronological creation of VRR and VTSs, intended and actual $(2014,2020-2022)$}

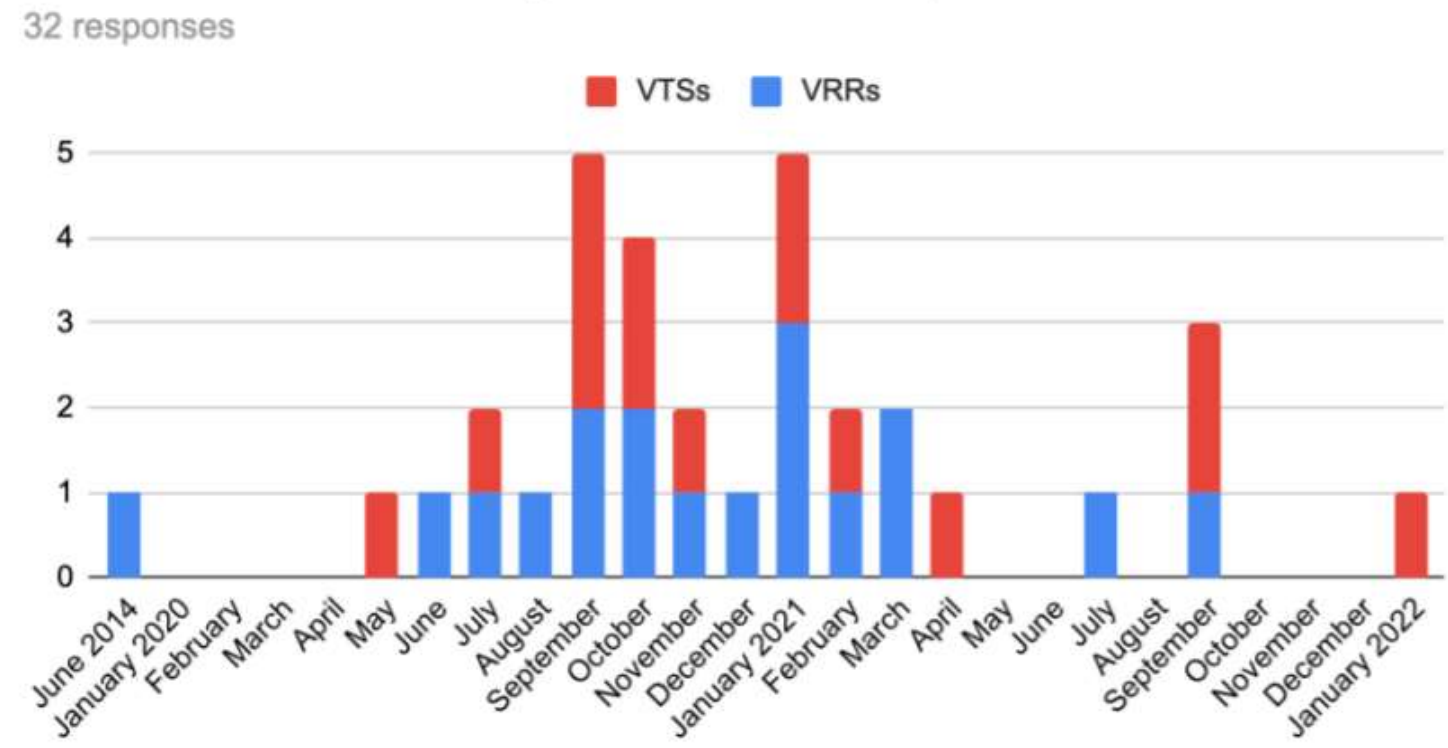

Fig. 3. Creation of VRR and VTSs [10]

Most of the institutions try to implement both VRR and VTS and they have different teams who manage these kinds of services.

During the pandemic period, VTSs represented an important support in the delivery of teaching and learning content, and they have become a very used method in universities for improving the on-line education.

\section{Virtual Exhibitions - One of the Ways to Mitigate the Impact of the Crisis}

Virtual exhibitions (VE) are among the several IT (Information Technology) implementations that are compatible with the fundamental concepts of Digital Humanism. The goal of this paper is to present the concepts and techniques of VE, with an emphasis on the modifications caused by the current COVID-19 epidemic.

A virtual exhibition developed at the Romanian Academy Library (figure 3) was analyzed using Google Analytics. 


\section{ROMÂNIA - FRANȚA - Itinerarii culturale Expoziţie virtuală}

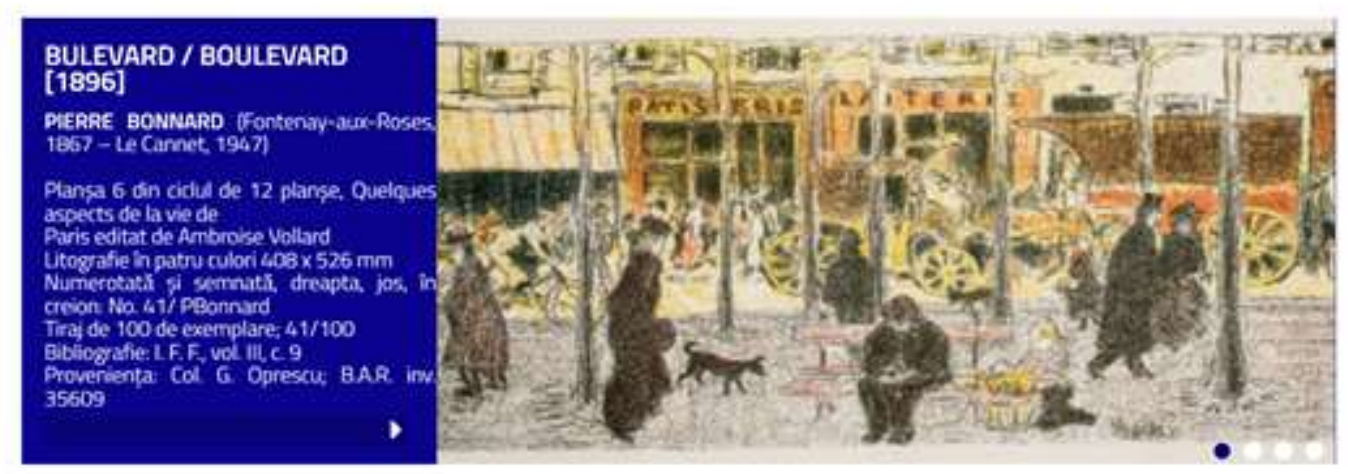

Fig. 3. A Virtual Exhibition at Romanian Academy Library

Given that the COVID-19 restrictions in The specific situation of Romania Romania began on March 22nd, 2020, we demonstrates an increase in the number of studied data before and after the restrictions. The statistics in Table 1 below are for both users and sessions following the periods, before and after March 22nd, 2020. implementation of COVID-19 limitations.

Table 1. Number of users and sessions per country and browser access

\begin{tabular}{|c|c|c|c|c|c|c|c|c|c|c|c|c|c|}
\hline \multirow[b]{2}{*}{ Country } & \multirow[b]{2}{*}{ Date Range } & \multicolumn{2}{|c|}{ Total } & \multicolumn{2}{|c|}{ Chrome } & \multicolumn{2}{|c|}{ Safari } & \multicolumn{2}{|c|}{ Android Webview } & \multicolumn{2}{|c|}{ Firefox } & \multicolumn{2}{|c|}{ Samsung Internet } \\
\hline & & Users & Sessions & Users & Sessions & Users & Sessions & Users & Sessions & Users & Sessions & Users & Sessions \\
\hline Romania & $\operatorname{Jan} 1,2018$ - Mar 22, 2020 & 857 & 1014 & 562 & 674 & 69 & 76 & 77 & \begin{tabular}{|l|}
84 \\
\end{tabular} & 70 & 93 & 26 & 27 \\
\hline Romania & Mar 23, 2020 - Jul 23, 2021 & 1186 & 1540 & 837 & 1102 & 132 & 177 & 10 & 10 & 82 & 97 & 63 & 72 \\
\hline United States & $\operatorname{Jan} 1,2018$ - Mar 22, 2020 & 53 & 53 & 4 & 4 & 41 & 41 & 1 & 1 & 1 & 1 & 0 & 0 \\
\hline United States & Mar 23, 2020 - Jul 23, 2021 & 51 & 53 & 10 & 10 & 36 & 38 & 0 & 0 & 2 & 2 & 0 & 0 \\
\hline Moldova & $\operatorname{Jan} 1,2018$ - Mar 22, 2020 & 30 & 38 & 22 & 26 & 4 & 4 & 0 & 0 & 1 & 1 & 1 & 5 \\
\hline Moldova & Mar 23, 2020 - Jul 23, 2021 & 34 & 44 & 25 & 29 & 3 & 3 & 0 & 0 & 2 & 2 & 3 & 9 \\
\hline |taly & $\operatorname{Jan} 1,2018$ - Mar 22, 2020 & 15 & 15 & 12 & 12 & 0 & 0 & 1 & 1 & 2 & 2 & 0 & 0 \\
\hline |taly & Mar 23, 2020 - Jul 23, 2021 & 18 & 19 & 11 & 11 & 3 & 3 & 1 & 1 & 2 & 3 & 0 & 0 \\
\hline Germany & $\operatorname{Jan} 1,2018$ - Mar 22, 2020 & 14 & 18 & 9 & 13 & 0 & 0 & 1 & 1 & 0 & 0 & 0 & 0 \\
\hline Germany & Mar 23, 2020 - Jul 23, 2021 & 15 & 21 & 7 & 10 & 4 & 7 & 0 & 0 & 4 & 4 & 0 & 0 \\
\hline United Kingdom & $\operatorname{Jan} 1,2018$ - Mar 22, 2020 & 12 & 14 & 5 & 7 & 2 & 2 & 4 & 4 & 0 & 0 & 0 & 0 \\
\hline United Kingdom & Mar 23, 2020 - Jul 23, 2021 & 17 & 17 & 10 & 10 & 3 & 3 & 1 & 1 & 0 & 0 & 2 & 2 \\
\hline France & $\operatorname{Jan} 1,2018$ - Mar 22, 2020 & 9 & 9 & 6 & 6 & 1 & 1 & 0 & 0 & 2 & 2 & 0 & 0 \\
\hline France & Mar 23, 2020 - Jul 23, 2021 & 13 & 13 & 6 & 6 & 3 & 3 & 0 & 0 & 4 & 4 & 0 & 0 \\
\hline Spain & $\operatorname{Jan} 1,2018$ - Mar 22, 2020 & 7 & 7 & 3 & 3 & 1 & 1 & 2 & 2 & 0 & 0 & 0 & 0 \\
\hline Spain & Mar 23, 2020 - Jul 23, 2021 & 7 & 7 & 5 & 5 & 0 & 0 & 1 & 1 & 1 & 1 & 0 & 0 \\
\hline Belgium & $\operatorname{Jan} 1,2018$ - Mar 22, 2020 & 4 & 4 & 1 & 1 & 0 & 0 & 2 & 2 & 0 & 0 & 0 & 0 \\
\hline Belgium & Mar 23, 2020 - Jul 23, 2021 & 5 & 6 & 3 & 4 & 1 & 1 & 0 & 0 & 1 & 1 & 0 & 0 \\
\hline Poland & $\operatorname{Jan} 1,2018$ - Mar 22, 2020 & 4 & 4 & 2 & 2 & 0 & 0 & 0 & 0 & 1 & 1 & 0 & 0 \\
\hline Poland & Mar 23, 2020 - Jul 23, 2021 & 5 & 10 & 3 & 8 & 0 & 0 & 0 & 0 & 0 & 0 & 0 & 0 \\
\hline Brazil & $\operatorname{Jan} 1,2018$ - Mar 22, 2020 & 3 & 3 & 2 & 2 & 0 & 0 & 0 & 0 & 0 & 0 & 1 & 1 \\
\hline Brazil & Mar 23, 2020 - Jul 23, 2021 & 5 & 6 & 2 & 2 & 0 & 0 & 0 & 0 & 0 & 0 & 3 & 4 \\
\hline Hungary & $\operatorname{Jan} 1,2018$ - Mar 22, 2020 & 3 & 3 & 1 & 1 & 0 & 0 & 0 & 0 & 2 & 2 & 0 & 0 \\
\hline Hungary & Mar 23, 2020 - Jul 23, 2021 & 9 & 15 & 4 & 4 & 0 & 0 & 0 & 0 & 5 & 11 & 0 & 0 \\
\hline
\end{tabular}


Because our analysis is focused on what happened in Romania, we colored with yellow, orange, red and green the number of users and sessions for different browsers accesses. In terms of total number of users and sessions, it was an increase after March 22nd, 2020, so after the restrictions and COVID-19 limitations were introduced. Regarding the most used browser, which has influence on types of devices from which the virtual exhibition was accessed, we see something interesting: Chrome registered an increase, while Android WebView a decrease after March 22nd, 2020.

If we check the data at the international level, there were no significant changes before and after the mentioned date, because the virtual exhibition taken into consideration it is wellknown in Romania, the content is in Romanian and, by consequence, the number of users from other countries was reduced.

According to Europeana DSI-4 Multilingual Strategy [5], in a virtual exhibition is recommended to integrate trusted vocabularies that come with existing multilingual coverage of metadata, as well as real-time translation services from English to fill translation gaps.

Figure 4 below presents how data evolved in terms of desktop versus mobile access.

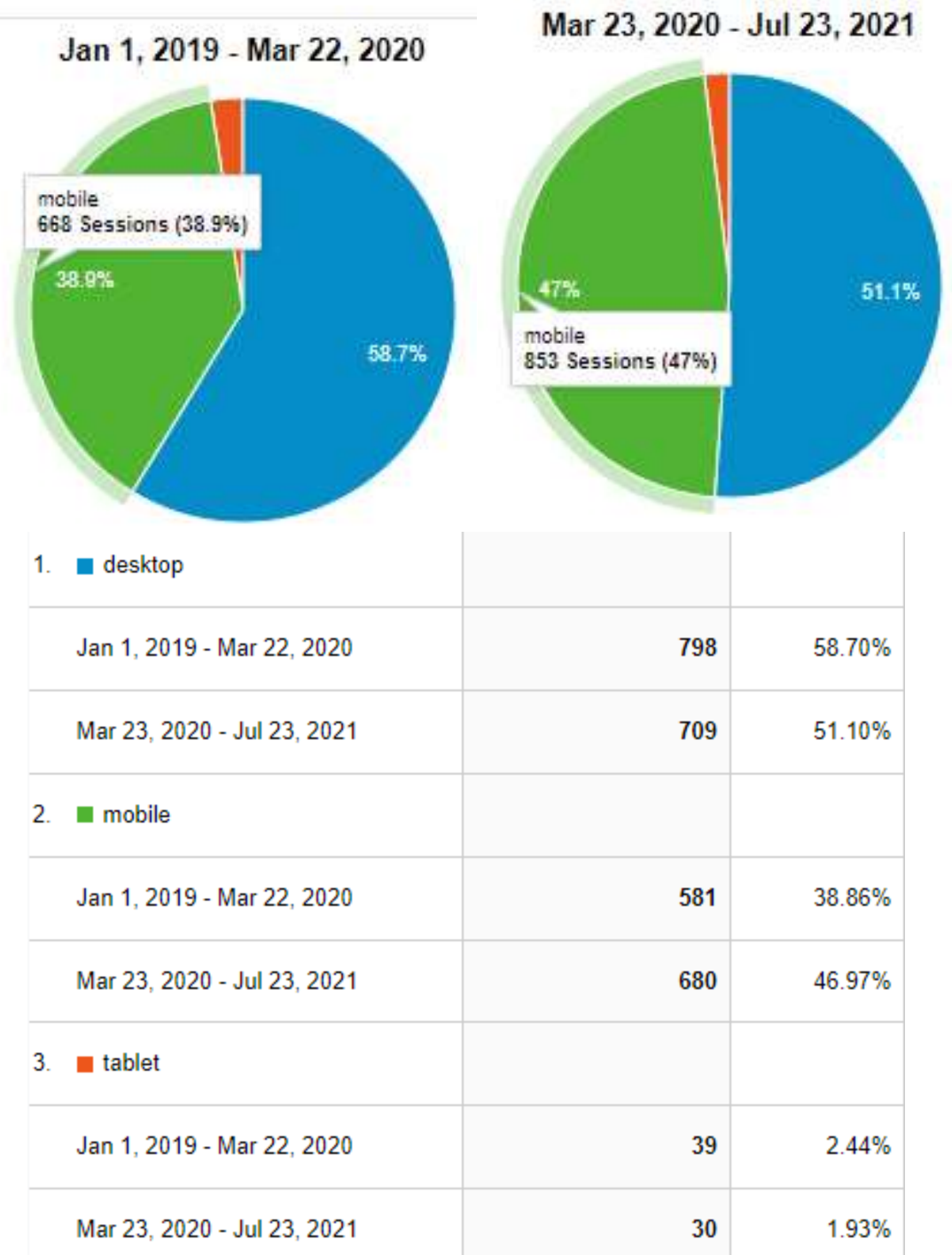

Fig. 4. Desktop versus mobile access for a virtual exhibition

Figure 4 shows that following the COVID-19 restrictions, the number of mobile sessions increased while the number of desktop sessions dropped. It's important to note that 
the number of tablet accesses has maintained at the same reduced level.

The use of tablets is not so high, even if for accessing a virtual exhibition it is recommended to use devices with big screens, in order to benefit from the experience provided by image galleries and storytelling solutions.

According to [6], the COVID-19 pandemic is more than a health issue. This is already a crisis with serious consequences for the most vulnerable individuals and professionals working in museums and other cultural institutions. During this time, many countries have attempted to implement virtual exhibitions, virtual reading rooms, virtual teaching spaces and so on, in order to mitigate losses caused by the closure of schools, museums, permanent physical exhibitions, as a result of worldwide societal prohibitions.

The benefits of virtualizing museum interiors to the audience in order to analyze certain crucial components that they would not have detected with the visual inspection within the structure are presented in [7], as are the constraints of such a depiction. One problem is that visitors to the museum will not get the same experience as they would at the actual place.

According with [8], the European Commission presented a vision and avenues for Europe's digital transformation by 2030 . The Commission encourages Member Countries to digitize all monuments and sites at risk of deterioration, as well as half of those heavily visited by tourists, by 2030 .

This recommendation will help to achieve the Digital Decade Goals by fostering a secure and sustainable digital infrastructure, training digital skills, and encouraging businesses, particularly SMEs, to use new technologies.

The European Commission has issued a recommendation [9] on a Common European Data Area for Cultural Heritage. The goal of this suggestion is to hasten the digitization of Europe's cultural resources.

The Committee considers that Member Countries accelerate the digitization of all monuments and sites, objects and artifacts of cultural identity for coming generations, take the appropriate preservation and protection measures for those in danger, and encourage the re-use of these digital collections in areas like education, sustainable tourism, and creative cultural industries [9].

\section{Conclusions}

In times of crises, culture is more vital than ever. In the context of unexpected and challenging conditions, culture is boosting our societies' resilience. The COVID-19 crisis's harmful effects on the cultural and creative sectors should be minimized.

Broadly speaking, due to the strong evidence provided here on the influence of societal and cultural backgrounds on young people's educational and technological outlooks, identifying the potential efficiency of any distributed decision-oriented or designoriented attempt from the standpoint of adjustment to the discussed contexts is highly valuable.

Despite being a pragmatic response to the lockdown of search rooms during the COVID19 outbreak, the development and implementation of Virtual Reading Rooms, Virtual Teaching Spaces and also Virtual Exhibitions has the potential to have a considerable impact on the conduct of collection-based studies across sectors. VRRs and VTSs provide interesting possibilities for collection-based research by enabling academics, students, and community members to participate in original teaching and research using physically distributed collections, and to communicate with these in an adaptable and humanly mediated manner. They also provide new chances for researchers and institutions to collaborate [3].

\section{References}

[1] L. Jones, Aho, "Resilience by Design," The Bridge, Vol. 49, Issue 2, July 1, 2019, Available at: https://www.nae.edu/212175/Resilienceby-Design

[2] McKinsey Agile resilience in the UK: Lessons fromCOVID-19 for the 'next normal', October 13, 2020, Available at: https://www.mckinsey.com/business- 
functions/organization/our-insights/agileresilience-in-the-uk-lessons-from-covid19-for-the-next-normal

[3] M. Greenhall, "New Frontiers of Digital Access: The development and delivery of Virtual Reading Rooms and Virtual Teaching Spaces amongst collectionholding institutions," Research Libraries UK, July 2021, Available at: https://www.rluk.ac.uk/wpcontent/uploads/2021/08/RLUK-VRRand-VTS-report.pdf

[4] J. Owsinski, C. Ciurea, F. G. Filip, "A Crowdsourcing Effort about Mobilizing Students to Forward Thinking of Their Studies," Informatica Economică , Vol. 24, No. 4, 2020, pp. 5-15.

[5] Europeana, Europeana DSI-4 Multilingual Strategy, October 12, 2020, Available at: https://pro.europeana.eu/post/europeanadsi-4-multilingual-strategy

[6] J. Cobley, D. Gaimster, S. So, K. Gorbey, K. Arnold, D. Poulot, \& M. Jiang, "Museums in the Pandemic: A Survey of Responses on the Current Crisis," Museum Worlds, Vol. 8, No. 1, 2020, pp. 111-134.

[7] A. Vajda, "Museums and Online Spaces. The Society-Building Role of the Museums during the Pandemic," Acta Universitatis Sapientiae, Communicatio, Vol. 7, 2020, pp. 42-53.

[8] European Commission, Europe's Digital Decade: digital targets for 2030, March 09, 2021, Available at: https://ec.europ.eu/info/strategy/priorities2019-2024/europe-fit-digital-age/europesdigital-decade-digital-targets-2030_en

[9] Europea Commission, Commission proposes a common European data space for cultural heritage, November 10, 2021, Available at: https://digitalstrategy.ec.europa.eu/en/news/commissio n-proposes-common-european-data-spacecultural-heritage

[10] M. Greenhall, New Frontiers of Digital Access: The development and delivery of Virtual Reading Rooms and Virtual Teaching Spaces amongst collectionholding institutions, 2021, Available at: https://www.rluk.ac.uk/wp-
content/uploads/2021/08/RLUK-VRRand-VTS-report.pdf

[11] G. Baxter, L. Beard, G. Beattie, M. Blake, M. Greenhall, K. Lingstadt, W.J. Nixon and T. Reimer, "Covid-19 and the Future of the Digital Shift amongst Research Libraries: An RLUK Perspective in Context," New Review of Academic Librarianship, November 2021, 27:3, pp. 322-348, DOI: 10.1080/13614533.2021. 1976232

[12] K. Miller and S. Sanchez-Gonzalez, "The Virtual Reading Room (VRR) at the University of Manchester Library", 2021, Available at: https://www.rluk.ac.uk/thevirtual-reading-room-vrr-at-theuniversity-of-manchester-library/.

[13] University of Oxford, Sounds of the Bodleian, 2021, Available at: https://www.ox.ac.uk/soundsofthebodleia $\mathrm{n} /$ \#radcam.

[14] Baxter, G. Case study: University of Reading - skills and leadership, Research Libraries, 2021, UK. Available at: https://www.rluk.ac.uk/university-ofreading-case-study-skills-and-leadership/.

[15] Slovak Economic Library, Virtual Reading Room EUBA, Available at: https://sek.euba.sk/en/services/virtualreading-room-euba

[16] C. Ni Lochlainn, "Virtual Trinity Library - A Major Digitisation Initiative of The Library of Trinity College's Collections Is Launched," 2021, Available at: https://www.tcd.ie/library/news/virtualtrinity-library-\%e2\%88\%92-a-majordigitisation-initiative-of-the-library-oftrinity-colleges-collections-is-launched/

[17] E. K. Smith, E. Kaya, 2021, Online University Teaching at the time of COVID19: An Australian Perspective, Special Issue: COVID-19: Education Response to a Pandemic, Volume 9 - Issue 2 - 2021, Available at: https://files.eric.ed.gov/fulltext/EJ129188 2.pdf

[18] L. Tapping, An Evaluation of Students' Experiences of Using Virtual Study Spaces, 2021, UCL (University College London): London, UK, Available at: 
https://discovery.ucl.ac.uk/id/eprint/10132 $327 /$

[19] T. Fiala, "Učebnice pre každého komplexný projekt CVTI SR pre zabezpečenie prístupu $\mathrm{k}$ študijnej literatúre na slovenských univerzitách / Textbooks for Everyone - A comprehensive Project of SCSI Providing Access to Study Literature for Slovak University Students," ITlib -
Information technology and libraries, 4/2018, pp. 12-15

[20] \#STILLSPECIAL: Virtual Reading Room Launch, 2020, Available at: https://collections.reading.ac.uk/specialcollections/2020/09/22/stillspecial-virtualreading-room-launch/

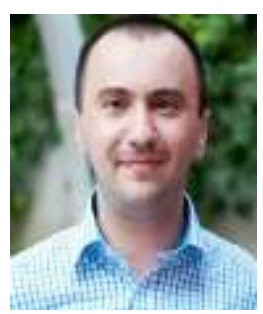

Cristian CIUREA is Professor at the Department of Economic Informatics and Cybernetics at Bucharest University of Economic Studies. He has graduated the Faculty of Economic Cybernetics, Statistics and Informatics at the Bucharest University of Economic Studies in 2007. He has a master in Informatics Project Management (2010) and a PhD in Economic Informatics (2011) at the University of Economic Studies, Bucharest. Cristian has a solid background in computer science and is interested in collaborative systems related issues. Other fields of interest include software metrics, data structures, object-oriented programming, windows applications programming, mobile devices programming and testing process automation for software quality assurance.

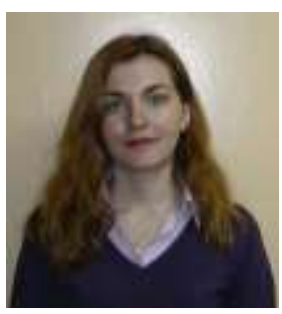

Lorena BĂTĂGAN has graduated the Faculty of Economic Cybernetics, Statistics and Informatics in 2002 when she has become teaching assistant. She is associate professor at the Department of Economic Informatics and Cybernetics at the Bucharest University of Economic Studies. She holds a $\mathrm{PhD}$ degree in Economic Cybernetics and Statistics since 2007. She is the author and co-author of 6 books and over 50 articles in journals and proceedings of national and international conferences and symposiums. 